\title{
Myostatin promotes the terminal differentiation of embryonic muscle progenitors
}

\author{
Marie Manceau, ${ }^{1}$ Jérôme Gros, ${ }^{1,4}$ Kathleen Savage, ${ }^{2}$ Virginie Thomé, ${ }^{1}$ Alexandra McPherron, ${ }^{2}$ \\ Bruce Paterson, ${ }^{3}$ and Christophe Marcelle ${ }^{1,5}$ \\ ${ }^{1}$ Developmental Biology Institute of Marseille Luminy (IBDML), CNRS UMR 6216, Université de la Méditerranée, Campus \\ de Luminy, 13288 Marseille Cedex 09, France; ${ }^{2}$ Genetics of Development and Disease Branch, The National Institute of \\ Diabetes and Digestive and Kidney Diseases (NIDDK)/National Institutes of Health, Bethesda, Maryland 20892, USA; \\ ${ }^{3}$ Laboratory of Biochemistry and Molecular Biology, National Cancer Institute, National Institutes of Health, \\ Bethesda, Maryland 20892, USA
}

\begin{abstract}
Myostatin, a TGF- $\beta$ family member, is an important regulator of adult muscle size. While extensively studied in vitro, the mechanisms by which this molecule mediates its effect in vivo are poorly understood. We addressed this question using chick and mouse embryos. We show that while myostatin overexpression in chick leads to an exhaustion of the muscle progenitor population that ultimately results in muscle hypotrophy, myostatin loss of function in chick and mouse provokes an expansion of this population. Our data demonstrate that myostatin acts in vivo to regulate the balance between proliferation and differentiation of embryonic muscle progenitors by promoting their terminal differentiation through the activation of $\mathbf{p} 21$ and MyoD. Previous studies have suggested that myostatin imposes quiescence on muscle progenitors. Our data suggest that myostatin's effect on muscle progenitors is more complex than previously realized and is likely to be context-dependent. We propose a novel model for myostatin mode of action in vivo, in which myostatin affects the balance between proliferation and differentiation of embryonic muscle progenitors by enhancing their differentiation.
\end{abstract}

[Keywords: Myostatin; skeletal muscle; embryo; p21]

Supplemental material is available at http://www.genesdev.org.

Received August 28, 2007; revised version accepted December 19, 2007.

Despite the rapid advance in the understanding of the molecules and mechanisms involved in regulating muscle differentiation in vertebrates, relatively little is known about the control of muscle size. In amniotes, all skeletal muscles of the body and the limbs derive from the dorsal compartment of somites, named the dermomyotome. In a first stage of muscle formation, cells arising from the four epithelial borders of the dermomyotome generate differentiated, post-mitotic myocytes that organize into the primitive skeletal muscle (named the primary myotome) located beneath the dermomyotome (Gros et al. 2004). During the second stage of muscle growth, the central portion of the dermomyotome undergoes an epithelial-to-mesenchymal transition (EMT). This triggers the invasion of the primary myotome by a population of muscle progenitors (Ben-Yair and Kal-

\footnotetext{
${ }^{4}$ Present address: Department of Genetics, Harvard Medical School, Boston, MA 02115, USA.

${ }^{5}$ Corresponding author.

E-MAIL marcelle@ibdm.univ-mrs.fr; FAX 33-4-91-82-06-82.

Article is online at http://www.genesdev.org/cgi/doi/10.1101/gad.454408.
}

cheim 2005; Gros et al. 2005). Long-term lineage analyses show that satellite cells, the major muscle stem cells of the adult, derive from the same dermomyotomal population (Gros et al. 2005; Kassar-Duchossoy et al. 2005; Relaix et al. 2005; Schienda et al. 2006). Early muscle progenitors are characterized by the expression of the transcription factors Pax3 and Pax7. These molecules have been shown to have a cooperative role in the specification of the muscle progenitor pool, since in mice deficient for both Pax3 and Pax7, all muscle progenitors are absent and muscle growth is consequently arrested (Kassar-Duchossoy et al. 2005; Relaix et al. 2005).

Once specified, muscle progenitors face a dual choice, as they can either proliferate or exit the cell cycle to terminally differentiate into contractile muscle fibers. The latter process requires the activation of the myogenic regulatory factors (MRFs: Myf5, MyoD, Myogenin, and MRF4) (for review, see Sabourin and Rudnicki 2000). During normal development, the process of muscle growth is continuous. Thus, a balance between proliferation and differentiation of muscle progenitor cells en- 
sures the maintenance of muscle progenitors and allows the constant and harmonious growth of all skeletal muscles. How this balance is regulated during embryogenesis is only partially understood. It was recently shown that mutant mouse embryos carrying mutations for Delta1 or RBP-J, two members of the Notch signaling pathway, display a premature increase in muscle differentiation that results in a rapid and complete exhaustion of the muscle progenitor cell population, eventually leading to a strong muscle hypotrophy (Schuster-Gossler et al. 2007; Vasyutina et al. 2007). Conversely, the overexpression of Delta 1 maintains chick muscle progenitors in an early undifferentiated, proliferative state (Delfini et al. 2000). These data show that the Notch signaling pathway plays an essential role in maintaining the muscle progenitor pool by preventing the premature activation of the myogenic differentiation.

A second key regulator of muscle growth is myostatin. In the adult, myostatin, a secreted factor of the TGF $\beta$ superfamily, has been shown to be a negative regulator of muscle size, since mutations that impair myostatin function in mice, cattle, and sheep result in a dramatic increase in muscle mass (Grobet et al. 1997; Kambadur et al. 1997; McPherron and Lee 1997; McPherron et al. 1997; Clop et al. 2006). A mutation in the myostatin gene was recently identified in human that results in decreased myostatin levels and leads to a phenotype similar to that observed in $\mathrm{mstn}^{-/-}$(myostatin-null) mice (Schuelke et al. 2004). Enlargement of the muscle mass was also observed when myostatin signaling was impaired in transgenic mice carrying a dominant negative form of the myostatin receptor (Lee and McPherron 2001) or in transgenic mice overexpressing follistatin, a secreted molecule that binds and inhibits myostatin (Matzuk et al. 1995; Lee and McPherron 2001; Amthor et al. 2004). In contrast, systemic administration of myostatin or specific overexpression in skeletal muscles induces a decrease in muscle mass (Zimmers et al. 2002; Reisz-Porszasz et al. 2003). Functional improvement of dystrophic muscles in mice has been attained by myostatin blockade (Bogdanovich et al. 2002). The nature of the improvement indicates that myostatin down-regulation might be beneficial for a variety of myopathies (such as muscular dystrophies), or muscle mass losses induced by disease, immobilization, or ageing. As a consequence, myostatin has become a potential therapeutical target in diseases involving muscle loss.

Numerous studies have investigated the effect of myostatin signaling on muscle cells. In vitro studies performed on cultured myogenic cell lines or primary myoblasts have shown that myostatin inhibits myoblast proliferation and activates the cyclin-dependent kinase inhibitor p21, which forces the withdrawal from the cell cycle (Thomas et al. 2000; Taylor et al. 2001; Rios et al. 2002; Joulia et al. 2003). In parallel, the activation of myostatin signaling is associated with a strong inhibition of myogenic differentiation (Langley et al. 2002; Rios et al. 2002; Joulia et al. 2003). Based on these results and the observation that satellite cells express myostatin and are quiescent (McCroskery et al. 2003), it has been suggested that the normal function of myostatin in adult muscle is to maintain satellite cells in a quiescent, undifferentiated state. However, this hypothesis has not yet been tested in an in vivo environment.

Similar conclusions have been reached for the embryonic function of myostatin. Myostatin is expressed in the developing mouse and chick embryo (McPherron et al. 1997; Amthor et al. 2002). Implantation of beads coated with high concentrations of myostatin protein within the developing limb buds of chick embryos induced the arrest of the proliferation of $\mathrm{Pax} 7^{+}$cells and the down-regulation of the MRFs, Myf5, and MyoD and of the early muscle progenitor marker Pax3 (Amthor et al. 2004, 2006). The proliferation arrest of the $\mathrm{Pax}^{+}$ muscle progenitors could be reversed when beads were removed from the limb buds (Amthor et al. 2006). It was thus suggested, as proposed for adult satellite cells, that the activation of myostatin signaling in the embryo results in the reversible quiescence of muscle progenitors and in an arrest of their myogenic differentiation program.

We recently developed an electroporation technique that allows us to target the expression of a gene of interest to the early embryonic muscle progenitors (Gros et al. 2005). Here, we take advantage of this technique to target the expression of myostatin or its inhibitors specifically to the muscle progenitor population and, using the coexpression of the GFP reporter gene as a lineage tracer, we quantified the relative contribution of muscle progenitors to muscle growth after myostatin gain or loss of function. This enabled us to analyze, in an in vivo environment, the cellular response of muscle progenitors to the alteration of myostatin signaling and the consequence of this response on the muscle tissue. We show here that while during normal development, a balance between the proportion of self-renewing muscle progenitors and differentiated, post-mitotic myofibers is maintained, the overexpression of myostatin in the somite surprisingly provokes a shift in this balance by increasing the proportion of differentiated muscle cells at the expense of the muscle progenitor pool. Conversely, the inhibition of myostatin signaling (with the use of its inhibitors follistatin or SMAD7) results in an expansion of the progenitor population, paralleled by a decrease in the proportion of differentiated muscle cells. Long-term gain-of-function experiments using RCAS retrovirus carrying the myostatin gene confirm the results obtained in the short-term studies and show that embryos exposed to prolonged myostatin overexpression maintain a reduced muscle progenitor pool. The sustained depletion of muscle progenitors in these embryos results in a marked muscle hypotrophy. The data obtained in the chick embryo are further supported by analyses carried on $\mathrm{mstn}^{-/-}$mouse embryos that demonstrate that the loss of myostatin function causes an increase in the proportion of muscle progenitors within the muscle masses. We show that myostatin overexpression in vivo does not lead to a significant change in the proliferation rate of muscle progenitors and that it activates MyoD expression. We find that $\mathrm{p} 21$ expression is activated after myo- 
statin overexpression in vivo. Coherent with the effect of myostatin overexpression, we show that the overexpression of p21 forces the progenitors to exit the cell cycle and to undergo premature differentiation that eventually results in a virtually complete depletion of the muscle progenitor population. Altogether, our data suggest that myostatin acts in vivo to modulate the balance between proliferation and differentiation of embryonic muscle progenitors during development. In the long term, such action controls the size of skeletal muscles. Importantly, we demonstrate that the overexpression of myostatin within the embryonic muscle masses does not inhibit the myogenic differentiation of muscle progenitors, as previously suggested by in vitro studies, but enhances their terminal differentiation. We demonstrate that the action of myostatin takes place only when muscle progenitors have entered the myogenic compartment. Altogether, these data underline the crucial importance of the environmental context in which myostatin signaling is acting. Our study thereby provides new insights into the cellular response to myostatin in vivo, significantly altering our view of its role in muscles.

\section{Results}

Proliferation and activation of the myogenic program in muscle progenitors

We recently identified the embryonic muscle progenitor population that is responsible for the growth of skeletal muscles (Gros et al. 2005). To lay the groundwork for functional studies, we first wanted to understand the precise sequence of molecular events characterizing muscle progenitors in the chick. For this, we electroporated the dorsal dermomyotome, where the muscle progenitors reside, with a GFP reporter gene. This enabled us to follow the progeny of the muscle progenitors over time and to distinguish them from primary myotome cells. We quantified the proportion of $\mathrm{GFP}^{+}$, dermomyotome-derived cells expressing the four chicken MRFs (Myf5, MyoD MRF4, and Myogenin), and the muscle progenitor markers Pax3 and Pax7. In parallel, we analyzed the proliferation status of these cells. Before the dermomyotome undergoes EMT, virtually all epithelial dermomyotome cells expressed Pax7 and Pax3 (Supplemental Fig. S1A-J) but none of the MRFs (Fig. 1B,F; Supplemental Fig. S2A,E). They were actively dividing, since $60 \%$ of the $\mathrm{Pax}^{+}$cells incorporated BrdU (Supplemental Fig. S1K,M). As they entered the myotome, the proliferation of $\mathrm{Pax}^{+}$cells significantly slowed down (34\% of $\mathrm{Brdu}^{+}$cells) (Supplemental Fig. S1L,M), and they underwent differentiation such that $84 \mathrm{~h}$ (3.5 d) after the electroporation of the GFP, they represented only $40 \%$ of the $\left(\mathrm{GFP}^{+}\right)$dermomyotome-derived cells (Fig. 1C-E,G-J; Supplemental Fig. S2B-D,F-H). At that time, the proportion of muscle progenitors relative to the entire dermomyotome progeny is reaching a plateau after an initial phase of massive differentiation (Gros et al. 2005). The proportion of $\mathrm{GFP}^{+} / \mathrm{MRFs}^{+}$cells increased progressively. At $3.5 \mathrm{~d}$ after electroporation, $60 \%$ of dermomyotome- derived cells expressed Myf5, while 30\% expressed MyoD or Myogenin, and only 10\% expressed MRF4 (Fig. $1 \mathrm{~J})$. This sequential order of MRFs activation is consistent with data obtained from genetic and cell culture studies in mouse (Sabourin and Rudnicki 2000; Buckingham et al. 2003).

We next investigated whether $\operatorname{Pax} 7^{+}$muscle progenitors expressed the MRFs. With time, an increasing number of demomyotome-derived cells expressed Pax7 and Myf5, such that $3.5 \mathrm{~d}$ after electroporation, most of them $(88 \%)$ coexpressed both genes; a small population of those $(12 \%)$ expressed Pax 7 only (Fig. 1E,J). In contrast, very few $\mathrm{Pax}^{+}$cells expressed any of the other three MRFs (Fig. 1I,J; Supplemental Fig. S2). An analysis of cell proliferation further uncovered that $\operatorname{Pax} 7^{+}$-only and $\mathrm{Myf}^{+} / \mathrm{Pax}^{+}$cells constituted the vast majority (83\%) of all proliferative cells within the myotome (Fig. 1K). The same was true at later stages of development (embryonic day 9 [E9]) (data not shown). In contrast, $\mathrm{MyoD}^{+}$and Myogenin $^{+}$dermomyotome-derived cells were poorly proliferative $\left(12 \%\right.$ and $13 \%$, respectively, of all $\mathrm{BrdU}^{+}$ cells); all $\mathrm{MyHC}^{+}$cells were post-mitotic (Fig. 1K). Together, these data identify $\operatorname{Pax} 7^{+}$-only, or $\operatorname{Pax} 7^{+} / \mathrm{Myf}^{+}$ cells as bona fide muscle progenitors, while $\mathrm{MyoD}^{+}$and Myogenin $^{+}$dermomyotome-derived cells constitute a population of myogenic cells that are clearly engaged in a terminal differentiation process.

Figure 1L summarizes the data presented above, showing the sequence of molecular events taking place in vivo, from the time of entry of muscle progenitors within the primary myotome until their differentiation into fully functional myocytes. These results set the framework for the study of myostatin in the regulation of proliferation and differentiation of the muscle progenitor population during development.

\section{Myostatin regulates the size of the muscle progenitor pool}

Myostatin has been identified as a critical factor in the regulation of muscle masses in the adult. While myostatin is expressed in differentiating muscles of mouse and chick embryos (McPherron et al. 1997; Amthor et al. 2002), its expression pattern and function have not been specifically addressed within the early muscle progenitor population that we recently identified (Gros et al. 2005). The knowledge of the exact timing and dynamics of muscle progenitor emergence and differentiation, together with our ability to target the expression of genes of interest within this cell population, enabled us to address these questions.

Myostatin is expressed at E3 in the central region of the dermomyotome, just prior to undergoing EMT (Fig. $2 \mathrm{~A}, \mathrm{~B})$. At E4.5, at a stage when the EMT of the dermomyotome is initiated, myostatin expression is observed in the dermomyotome and in the dorsal-most portion of the myotome (Fig. 2E,F). This expression pattern follows the dynamics of the muscle progenitor migration within the primary myotome (see Fig. 1A; Gros et al. 2005), strongly suggesting a role for myostatin in the 

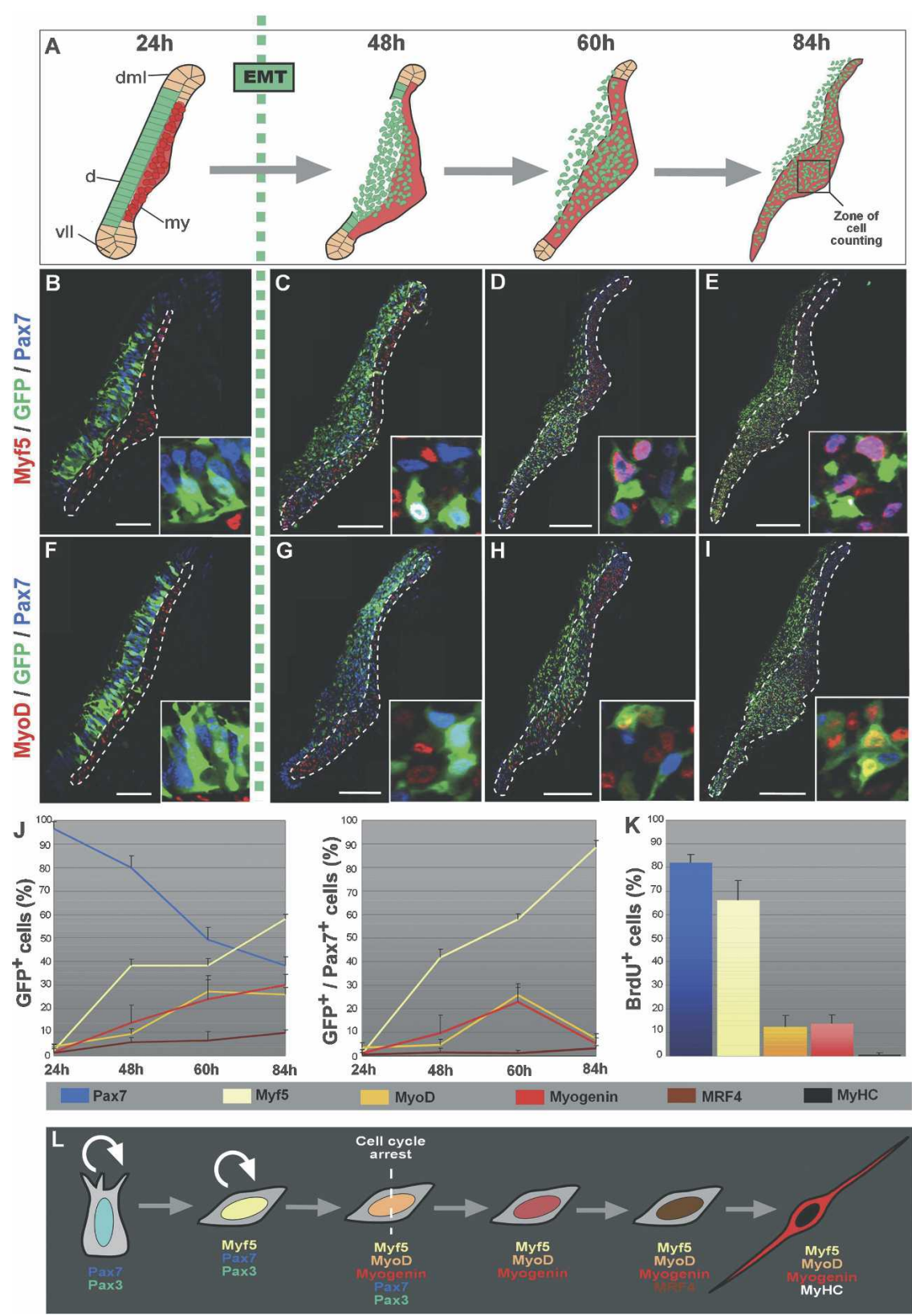

Figure 1. Molecular characterization of the muscle progenitor cell population. $(A)$ The emergence of the muscle progenitor cell population during muscle formation. Epithelial cells of the central-most part of the dermomyotome (in green) undergo an EMT and massively invade the primary myotome (in red), where they proliferate and differentiate into muscle fibers. (d) Dermomyotome; (my) myotome; (vll) ventro-lateral lip; (dml) dorso-medial lip. The $24 \mathrm{~h}, 48 \mathrm{~h}, 60 \mathrm{~h}$, and $84 \mathrm{~h}$ correspond to the time after somite formation $(B-I)$, Confocal optical views of transverse sections through interlimb somites $24 \mathrm{~h}(B, F), 48 \mathrm{~h}$ $(C, G), 60 \mathrm{~h}(D, H)$, or $84 \mathrm{~h}(E, I)$ after electroporation of the GFP reporter gene in the central portion of the dermomyotome. The primary myotome is delineated by white dotted lines. Insets at the bottom right show a few electroporated cells in the central part of the dermomyotome $(B, F)$ and the myotome $(C-E, G-I)$. We counted the number of cells stained for GFP, Pax7, and Myf5 $(B-E)$ or MyoD $(F-I)$, in a region corresponding to a central domain of the myotome (black square in $A$ ). $(J)$ Quantifications of the proportion of cells (arising from the central dermomyotome) that express each molecular marker. Cell counts are expressed as a percentage of the total number of $\mathrm{GFP}^{+}$(left) or $\mathrm{GFP}^{+}$) $\operatorname{Pax} 7^{+}$(right). For each time point, $\geq 10$ sections were counted, corresponding to a number of cells comprised between 200 and 300 cells at $24 \mathrm{~h}$, and between 1000 and 2000 at 48, 60, and 84 h. Error bars indicate standard deviation. Most $\mathrm{GFP}^{+}$ cells express Pax7 before the EMT, and sequentially initiate the expression of Myf5, MyoD, Myogenin, MRF4, and MyHC. $\mathrm{GFP}^{+} / \mathrm{Pax}^{+}$muscle progenitors progressively activate Myf5. The proportion of $\mathrm{MyoD}^{+}$and Myogenin ${ }^{+}$increases to reach $20 \%$ at $60 \mathrm{~h}$, and then decreases $84 \mathrm{~h}$ after somite formation. MRF4 is almost not expressed by muscle progenitors at this time of development. $(K)$ Quantification of the expression of Pax7, Myf5, MyoD, Myogenin, or MyHC in proliferating BrdU ${ }^{+}$cells. Most proliferating cells express Pax7 and Myf5 ( $82 \%$ and $65 \%$, respectively). Only $12 \%$ and $13 \%$ express MyoD and myogenin, respectively. No BrdU ${ }^{+}$cells express $M y H C$. $(L)$ Schematic of the myogenic program followed by embryonic muscle progenitors. (d) Dermomyotome; (my) myotome. Bars: $B, F, 50 \mu m$; $C, G, 100 \mu \mathrm{m} ; D, E, H, I, 200 \mu \mathrm{m}$.

regulation of the fate of embryonic muscle progenitors as they enter the muscle masses. Interestingly, follistatin displays a complementary pattern, surrounding the zones of myostatin expression, consistent with a role in limiting the range of myostatin action (Fig. 2C-H). Myostatin mRNA is detected within the muscle masses of older embryos (at E6) (Fig. 2I), suggesting that this molecule could act throughout embryogenesis. The myostatin receptor ActivinRIIB and the negative effector of myostatin signaling SMAD7 are also expressed in the somites when muscle progenitors undergo their differen- tiation (data not shown). Thus, the expression patterns of the members of the myostatin signaling pathway are consistent with a role in the molecular regulation of the differentiation of muscle progenitors.

To test this, we targeted myostatin expression within this cell population by electroporating plasmids containing the murine form of myostatin together with the GFP reporter gene into the central part of the dermomyotome. Taking advantage of the GFP expression as a tracer, we quantified the contribution of the muscle progenitor population to muscle growth when myostatin 


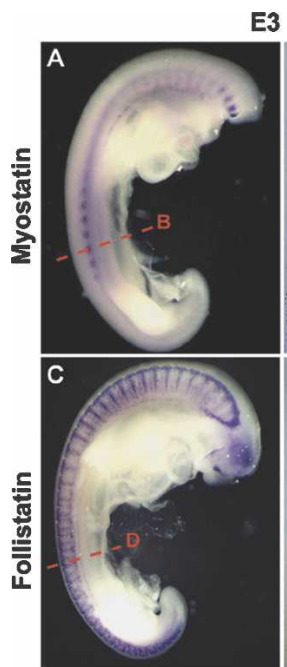

mGFP + 84h

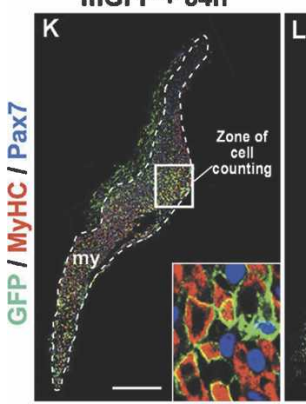

Myostatin $+84 h$

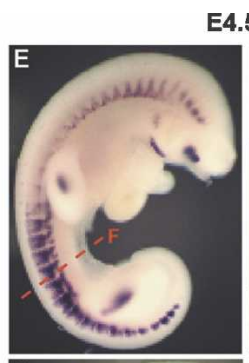

E4.5
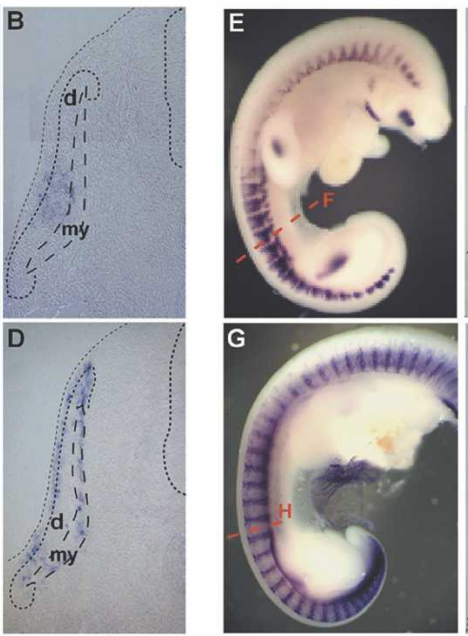

Follistatin $+84 \mathrm{~h}$

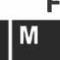

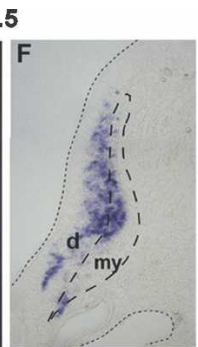
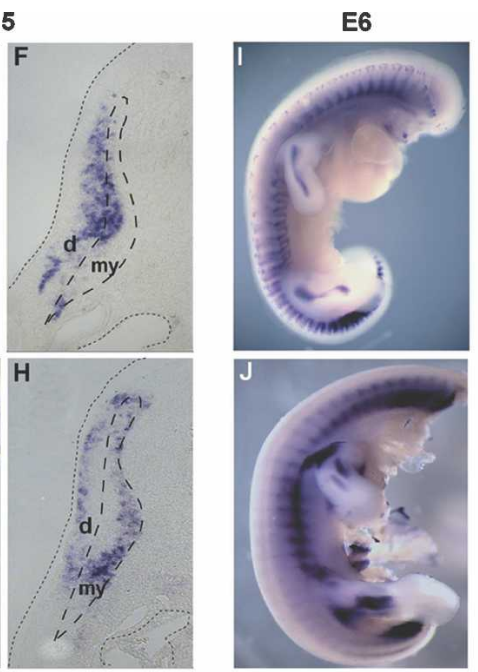

SMAD7 +84h
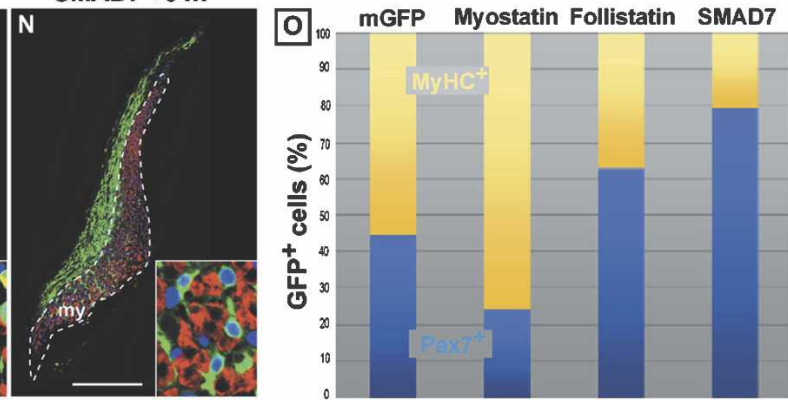

Figure 2. Myostatin signaling reduces the muscle progenitor pool. $(A-J)$ In situ hybridizations using probes directed against cmyostatin $(A, B, E, F, I)$ and c-follistatin $(C, D, G H, J)$, at E3 $(A-D), \mathrm{E} 4.5(E-H)$, and $\mathrm{E} 6(I, J) .(A)$ Myostatin is expressed in the interlimb somites at E3. $(E, I)$ Later in development, myostatin expression is detected in all somites and in the muscle masses of the limb. $(B, F)$ Sections in the trunk region (corresponding to red dotted lines in $A$ and $E$ ) of stained embryos show that myostatin expression is restricted to the central-most part of the dermomyotome at E3 $(B)$, and, later, to the de-epithelializing dermomyotome and the myotome $(F) .(C, D, G, H, J)$ Follistatin is expressed in a complementary pattern to that of myostatin. $(D, H)$ Transverse sections $($ see red dotted lines in $C$ and $G$ ) show that follistatin expression pattern in the dermis and the ventral-most part of the myotome surrounds myostatin-expressing regions (cf. $B$ and $D$, and $F$ and $H) .(K-N)$ Transverse sections, $84 \mathrm{~h}(3.5 \mathrm{~d})$ after dorsal electroporation, of constructs coding for a membranal form of the GFP (as a control) $(K)$, mMyostatin $(L)$, cFollistatin $(M)$, or mSMAD7 (N), and stained with GFP (green), Pax7 (blue), or MyHC (red) antibodies. (O) The number of GFP ${ }^{+}$cells stained for either Pax7 (light blue) or MyHC (yellow) were counted in a central domain of the myotome (white square in $K$ and black square in Fig. 1A). Insets in $K-N$ show enlargements of the zone of counting. Cell counts are expressed as a percentage of $\mathrm{GFP}^{+}$cells. In control embryos, $40 \%$ of $\mathrm{GFP}^{+}$cells express Pax7, whereas 60\% express MyHC (2500 cells counted). After Myostatin overexpression, significantly less GFP ${ }^{+}$cells express Pax7 $(23 \%)$ and more express MyHC $\left(77 \%, 5500\right.$ cells counted, $\left.P<10^{-4}\right)$. Follistatin and SMAD7 overexpression have the reverse effect with an increase in $\mathrm{Pax}^{+}$cells $\left(62 \%\right.$ and $79 \%$, respectively) at the expense of $\mathrm{MyHC}^{+}$cells $(38 \%$ and $21 \%$, 6900 and 2000 cells counted, $P<10^{-4}$ and $P<10^{-3}$, respectively). (d) Dermomyotome; (my) myotome. Bars: $K-N, 200 \mu \mathrm{m}$.

signaling is altered. This analysis was performed $3.5 \mathrm{~d}$ after electroporation, (Fig. 2K-O). Myostatin overexpression resulted in a significant decrease in the proportion of $\mathrm{Pax}^{+} / \mathrm{GFP}^{+}$cells and in an increase in the proportion of $\mathrm{MyHC}^{+} / \mathrm{GFP}^{+}$cells (Fig. 2L,O) as compared with the control situation (Fig. 2K). In contrast, the targeted expression of the myostatin inhibitors follistatin or SMAD7 in muscle progenitors resulted in a robust decrease in the proportion of differentiated cells, accompanied by an expansion of the progenitor pool (Fig. 2M-O). We also observed that the overexpression of SMAD7 altered the migration of the dermomyotome cells into the myotome compartment (Fig. 2N). This effect is unlikely to be specific of myostatin signaling, as the overexpres- sion of myostatin or follistatin does not affect the migration of muscle progenitors (data not shown) and might rather be due to the inhibition by SMAD7 of the signaling pathway(s) of other members of the TGF $\beta$ superfamily secreted within and around the somitic compartment. Taken together, these data indicate that myostatin signaling acts, within the early embryonic muscle compartment, to decrease the size of the embryonic muscle progenitor pool by promoting their myogenic differentiation.

\section{Myostatin controls the size of embryonic muscles}

We next tested the long-term effect of gain or loss of myostatin signaling in the embryo. In order to provide a 
prolonged exposure to Myostatin signaling, we electroporated the central region of the dermomyotome with the GFP reporter gene together with an avian retrovirus (RCAS) construct carrying the myostatin cDNA. Two days after the electroporation, myostatin was strongly overexpressed in the somites (data not shown). We analyzed the embryos that were strongly electroporated (as visualized by GFP expression) at E9; i.e., $6.5 \mathrm{~d}$ after the beginning of retroviral infection (Fig. 3A-J). Compared with control embryos infected with empty retroviruses (Fig. 3A-E), embryos infected with myostatin-carrying retroviruses displayed a deficit in muscle fibers that was particularly prominent in the hypaxial muscles. Moreover, we observed that the muscle masses contained fewer $\mathrm{Pax}^{+}$muscle progenitors (Fig. 3F-J). These data show that the sustained acceleration of muscle progenitor differentiation in response to ectopic myostatin expression results in a depletion of the embryonic muscle progenitor pool and in a major reduction in muscle mass. We next analyzed the muscle progenitor population in myostatin-deficient mice. For this we quantified the relative proportion of muscle progenitors present within
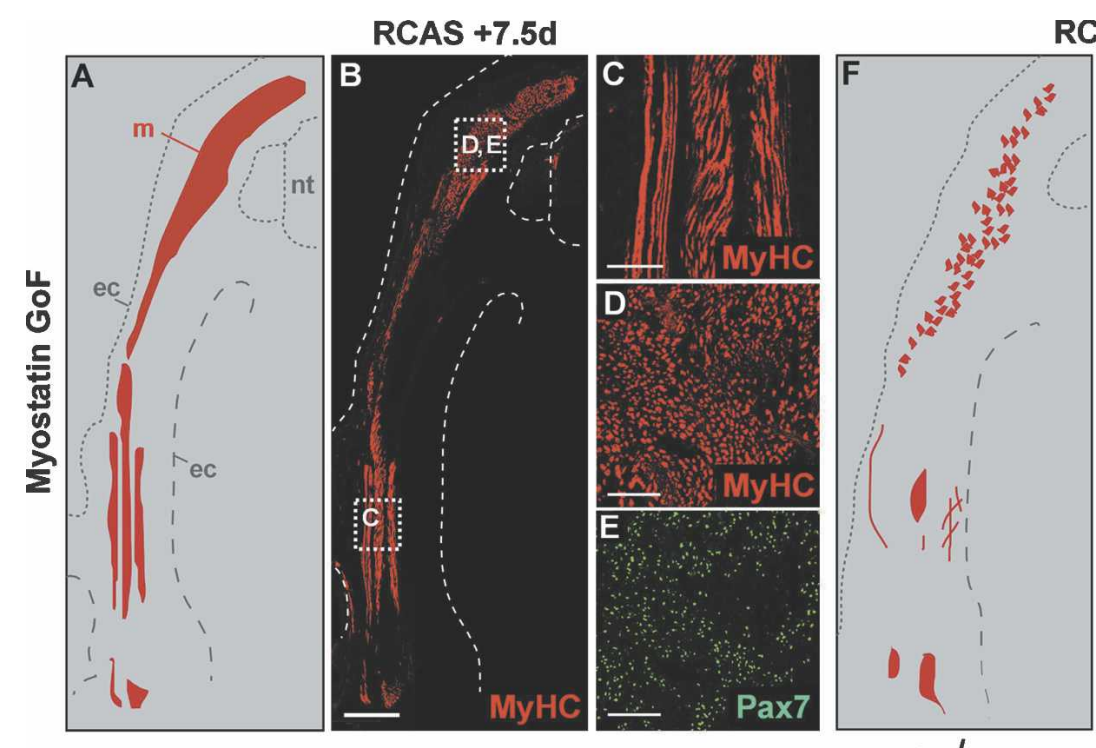

RCAS-Myostatin +7.5d
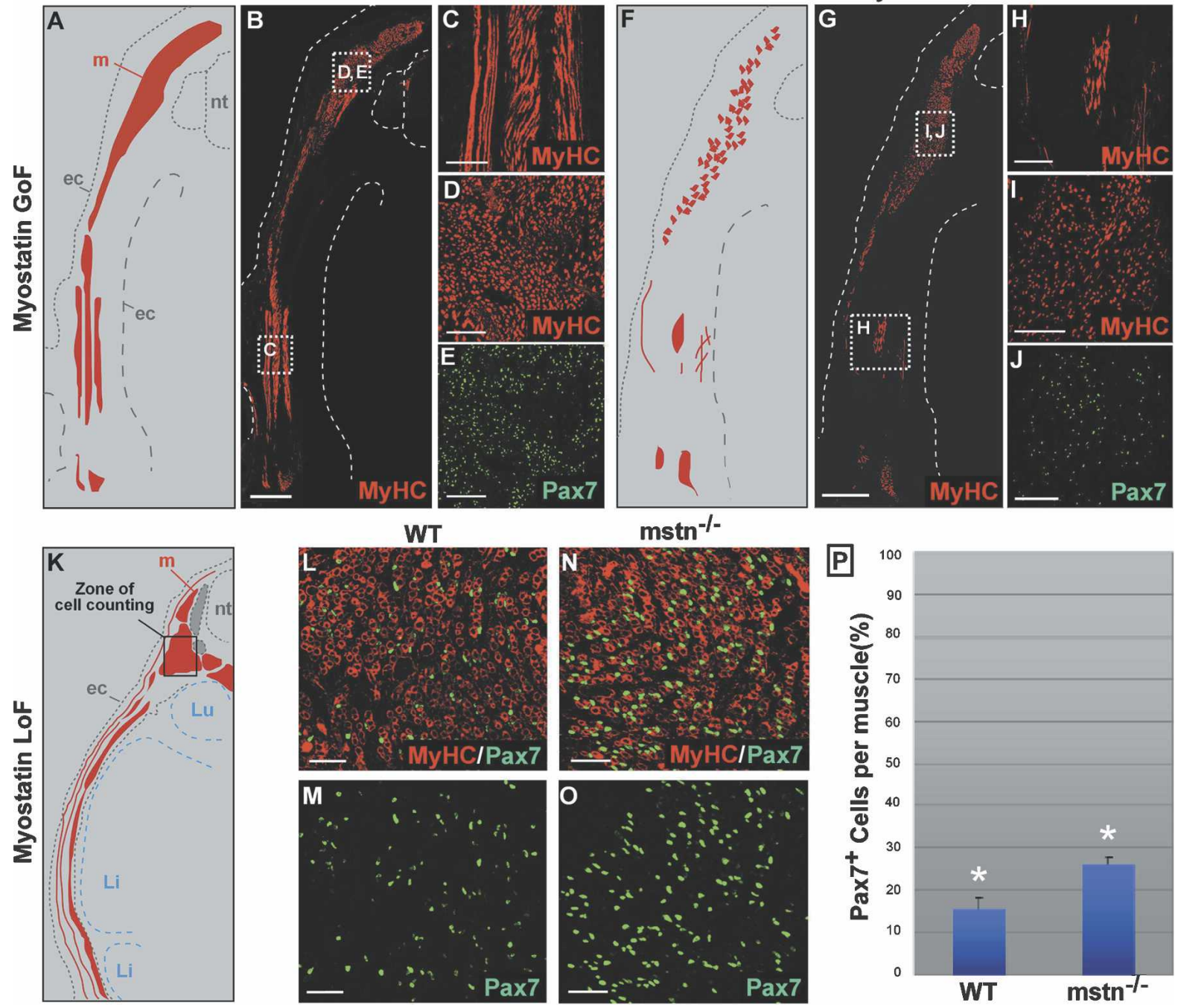

Figure 3. Myostatin regulates the size of the embryonic muscles in amniotes. $(A-I)$ The central dermomyotome was coelectroporated with retroviral constructs containing the murine form of the myostatin cDNA together with a GFP reporter and was analyzed 7.5 d after electroporation. $B-E$ show the muscle masses, stained with $\mathrm{MyHC}$ (in red), of an embryo electroporated with an empty RCAS vector as a control. $C, D$, and $E$ are enlargements of white squares in $B$, showing that muscle masses strongly express $M y H C(C, D$, in red), and $\operatorname{Pax} 7(E$, in green). $n=2 . A$ is a scheme representing the muscle masses (in red) shown in $B$. $(F-I)$ Electroporation of RCAS-Myostatin leads to a drastic reduction of lateral muscles $(H)$ and a reduction in the expression of $\mathrm{MyHC}(H, I)$ and $\mathrm{Pax} 7(J) . n=2$.

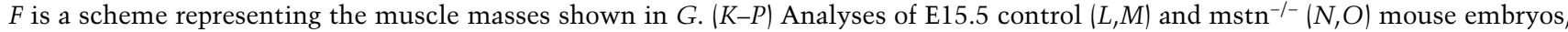
stained for $\operatorname{MyHC}\left(L, N\right.$, in red) and $\operatorname{Pax} 7\left(L-O\right.$, in green). $(P)$ We found that there is a $10 \%$ difference in the proportion of Pax $7^{+}$muscle progenitors in epaxial muscle masses of control $(L, M)$ and $\operatorname{mstn}^{-/-}(N, O)$ embryos $\left(\geq 10,000\right.$ cells counted, $\left.P<10^{-2}\right)$. Error bars indicate standard deviation. $K$ is a scheme representing muscle masses at E15.5 (in red). Black square in $K$ shows the zone of cell counting. (nt) Neural tube; (my) myotome, (ec) ectoderm; (Li) liver; (Lu) lung. Bars: B,G, $500 \mu \mathrm{m} ; C, D, E, H-I, 100 \mu \mathrm{m} ; L-O, 50 \mu \mathrm{m}$. 
the muscle masses of mouse mstn $^{-/-}$embryos at E15.5 (i.e., $\sim 4 \mathrm{~d}$ after the progenitor population has entered the mouse primary myotome) (Fig. $3 \mathrm{~K}-\mathrm{O}$ ). At this stage, $\mathrm{mstn}^{-/-}$mutant mice exhibited a significant increase in the proportion of $\mathrm{Pax}^{+}$cells present per muscle $1+10 \%$, $P<10^{-2}$ ) (Fig. 3P). This result demonstrates that the absence of myostatin provokes an increase in the proportion of muscle progenitors present within muscles in the embryo, which accounts for the increase in the number of muscle fibers that has been observed in myostatin mutant mice after birth. Together, these results obtained in two distinct model organisms strongly support a model whereby myostatin signaling limits the number of muscle progenitors, which in turn is critical to determine the embryonic muscle size.

\section{Myostatin promotes the initiation of MyoD expression} in muscle progenitors

Our results show that myostatin promotes the terminal differentiation of muscle progenitor cells into $\mathrm{MyHC}^{+}$ muscle fibers. This is in disagreement with previous studies showing that Myostatin signaling imposes quiescence on muscle progenitors of the limb by inhibiting both the cell division and the activation of the MRFs Myf5 and MyoD (Amthor et al. 2006). Given this discrepancy, we used the electroporation technique to assess the proliferation rate of somitic and $\operatorname{limb} \mathrm{Pax} 7^{+}$ muscle progenitors exposed to myostatin over a long period of incubation. We quantified the ratio of $\mathrm{BrdU}^{+}$ $\left(\mathrm{Pax}^{+}\right)$versus $\mathrm{BrdU}^{-}\left(\mathrm{Pax}^{+}\right)$muscle progenitors $3.5 \mathrm{~d}(84$ h) after GFP (as a control) (Fig. 4A) or myostatin (Fig. 4B) electroporation in the central part of the dermomyotome. In control embryos, $\sim 33 \%$ of the $\left(\mathrm{GFP}^{+} / \mathrm{Pax}^{+}\right)$ somitic muscle progenitors were proliferating (Fig. $4 \mathrm{C}$; Supplemental Fig. S1M). This proportion was not significantly changed when myostatin was overexpressed $(28 \%, P>0.05)$ (Fig. 4C). To test whether muscle progenitors in the limb respond to myostatin signaling as those of the trunk, we electroporated the GFP alone (Supplemental Fig. S4A-C) or myostatin (Supplemental Fig. S4D-F) in the lateral part of the somite, from where limb muscle progenitor cells originate. Forty-eight hours after electroporation, GFP- (control) or myostatin-overexpressing muscle progenitor cells had migrated into the limb bud mesenchyme and were observed in the dorsal and the ventral muscle masses (Supplemental Fig. S4A,D). We did not observe a modification of the proportion of $\mathrm{BrdU}^{+} / \mathrm{Pax}^{+}$proliferative muscle progenitors after myostatin overexpression (Supplemental Fig. S4E,F) when compared with the control side (Supplemental Fig. $S 4 B, C)$. The same results were obtained when myostatin was provided to muscle progenitors as an external source by electroporating the myostatin construct in the $\operatorname{limb}$ bud mesenchyme cells (data not shown). Taken together, our results show that myostatin signaling does not significantly modify the proliferation rate of trunk and limb muscle progenitors in vivo.

Having shown that Myostatin in the short term induces terminal differentiation in the embryonic muscle, we wanted to identify the specific step of the differentiation program affected by the modulation of myostatin signaling. To do this, we referred to our descriptive analysis of the molecular hierarchy, which takes place during the differentiation of muscle progenitors (Fig. 1L). We first tested whether the progenitor cell identity is altered prior to the dermomyotome EMT. Twenty-four hours after the overexpression of myostatin, the electroporated $\mathrm{GFP}^{+}$cells that were still located within the dermomyotome remained epithelial. As in control embryos, the myostatin ${ }^{+} / \mathrm{GFP}^{+}$cells expressed Pax7 and were negative for Myf5 and MyoD expression (Fig. 4D-F). These results show that myostatin overexpression does not affect the progenitor identity, and does not lead to an ectopic activation of the myogenic program within the epithelial dermomyotome. We then analyzed whether myostatin signaling activates the expression of Myf5 in $\mathrm{Pax}^{+}$muscle progenitors, as this activation is the first step of the myogenic differentiation program after the entry of the progenitors into the myotome compartment (see Fig. 1L). To do this, we quantified the ratio of Myf5 ${ }^{+}$ $\left(\mathrm{Pax}^{+}\right)$versus $\mathrm{Myf5}^{-}\left(\mathrm{Pax}^{+}\right)$progenitors present in the myotome compartment $3.5 \mathrm{~d}$ after electroporation of either myostatin (Fig. 4H) or SMAD7 (Fig. 4I) in the central part of the dermomyotome. Although the total population of $\mathrm{Pax}^{+}$muscle progenitors was greatly affected after electroporation of Myostatin or SMAD7, as demonstrated above (Fig. 2K-O), the relative proportion of $\mathrm{Myf5}^{+}$and $\mathrm{Myf5}^{-}$progenitors did not change in any of the experimental conditions (Fig. 4J), indicating that myostatin signaling does not regulate the initiation of Myf5 expression. The initiation of MyoD expression in $\mathrm{Pax}^{+}$muscle progenitors marks the second step of the myogenic differentiation program (see Fig. 1L). As mentioned above, few dermomyotome-derived cells coexpress MyoD and Pax7 $3.5 \mathrm{~d}$ after electroporation under normal conditions (Figs. 1J, 4K,N). However, when myostatin was overexpressed, the proportion of $\mathrm{MyoD}^{+} /$ $\operatorname{Pax} 7^{+}$cells was significantly larger when compared with the control (Fig. 4L,N), while it was significantly smaller when SMAD7 was electroporated (Fig. 4M,N). Thus, within the embryonic muscle environment, myostatin signaling promotes the initiation of the terminal differentiation by activating MyoD expression in $\operatorname{Pax} 7^{+} / \mathrm{Myf}^{+}$ muscle progenitors.

\section{Myostatin-induced depletion of the muscle progenitor population is mediated by cell cycle withdrawal through the activation of $c d k$ p21}

In vitro studies have shown that one of the targets of myostatin signaling is $\mathrm{p} 21$, a cdk inhibitor that regulates the $\mathrm{G} 1 / \mathrm{S}$ and the G2/M transitions during cell cycle (Dulic et al. 1998; Sherr and Roberts 1999; Thomas et al. 2000). Whether myostatin regulates p21 in vivo is unknown. We thus examined the expression of p21 after myostatin electroporation in muscle progenitors in vivo. In contralateral nonelectroporated somites, p21 expression was detected $24 \mathrm{~h}$ after somite formation in the epithelial borders of the dermomyotome, but not in its 

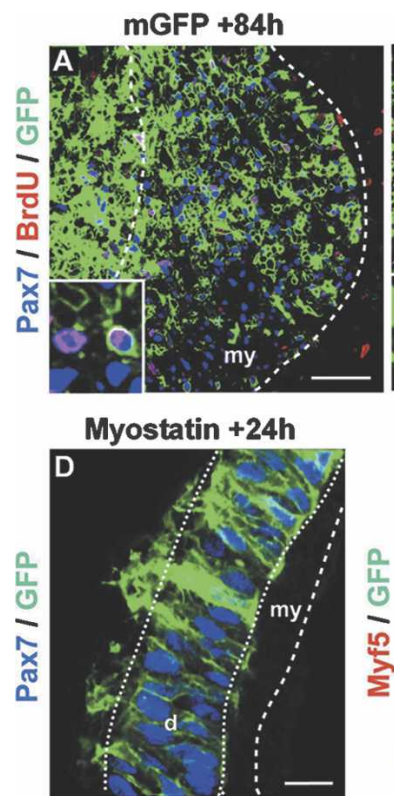

mGFP +84h
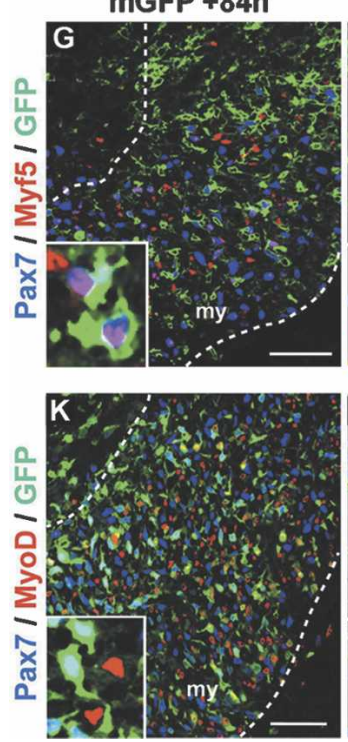

Myostatin $+84 \mathrm{~h}$

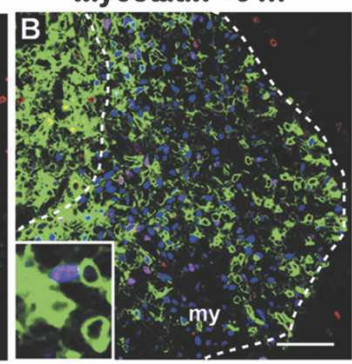

Myostatin +24h

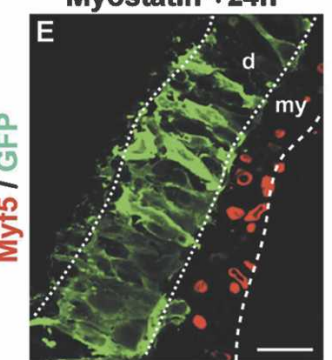

Myostatin $+84 \mathrm{~h}$
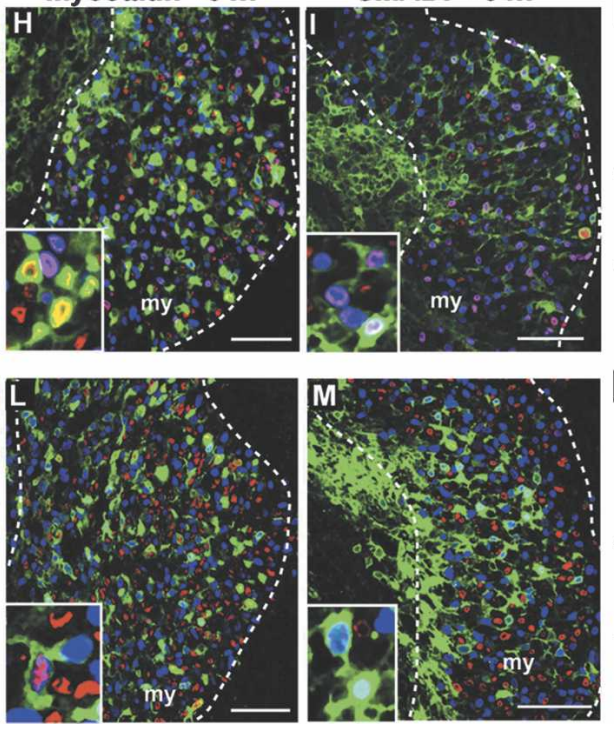

SMAD7 +84h

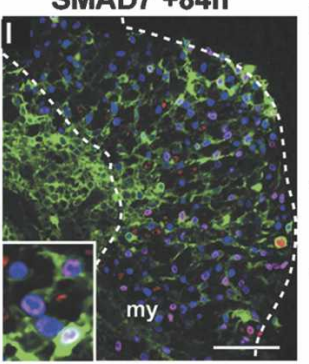

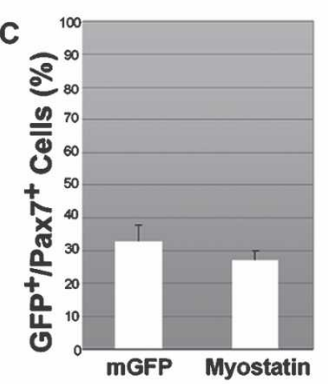

Myostatin +24h
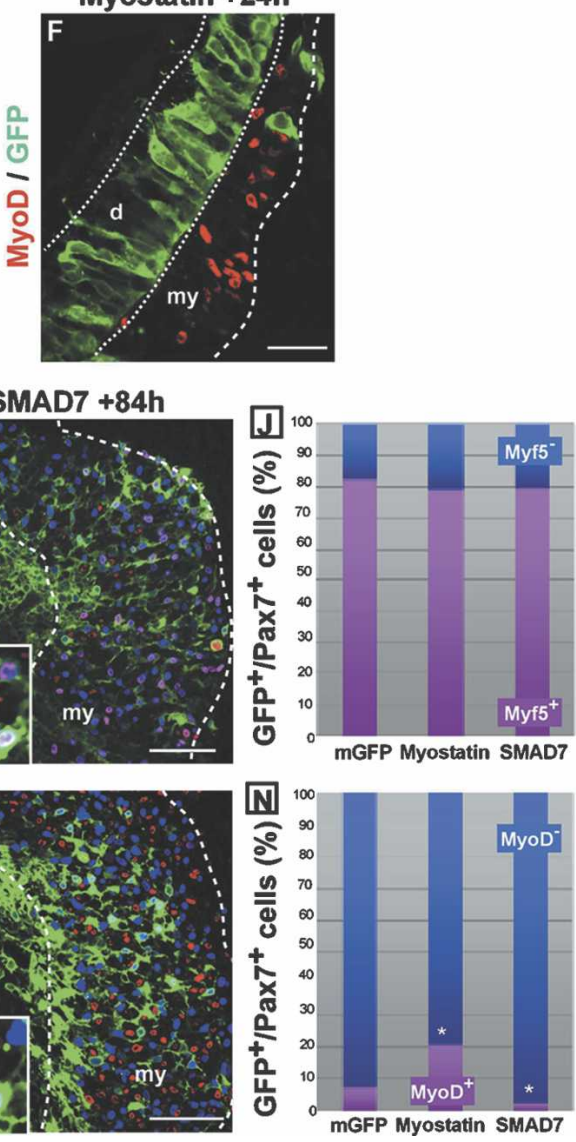

Figure 4. Myostatin signaling induces MyoD expression in muscle progenitors. $(A-C)$ Transverse confocal views of the central part of the myotome (black square in Fig. 1A) stained with Pax7 (in blue), BrdU (in red), and GFP (in green) antibodies. (C) Quantification experiments showing that there is no significant difference in the proportion of proliferative progenitors $84 \mathrm{~h}$ after the electroporation of a control $(A)$ or a Myostatin $(B)$ construct $(33 \%$ and $28 \% ; 1000$ and 2000 cells counted, respectively; $P>0.05)$. Cell counts are expressed as a percentage of $\mathrm{GFP}^{+} / \mathrm{Pax}^{+}$cells. Insets at the bottom left of $A$ and $B$ are enlargements showing a few electroporated cells. $(D-F)$ Transverse confocal views of epithelial dermomyotomes $24 \mathrm{~h}$ after electroporation with a Myostatin/GFP construct. Myostatinexpressing cells (in green) within the dermomyotome express Pax7 (D, in blue) and do not prematurely induce Myf5 (E) or MyoD $(F)$ (in red). $(G-M)$ Central regions of myotomes (black square in Fig. 1A), $84 \mathrm{~h}$ after membranal GFP $(G, K)$, myostatin $(H, L)$, or SMAD7 $(I, M)$ electroporation. The sections were stained for GFP (in green), Pax7 (in blue), and Myf5 (G-I), or MyoD (K-M) (in red). Insets at the bottom left are enlargements of $G-M$ showing a few electroporated cells. $(J, N)$ We determined the proportion of $\mathrm{GFP}^{+} / \mathrm{Pax}^{+}$muscle progenitors that express Myf5 $(J)$ or MyoD $(N)$. $(J)$ Cell counts are expressed as a percentage of $\mathrm{GFP}^{+} / \mathrm{Pax} 7^{+}$cells. There is no significant differences in the proportion of $\mathrm{Myf5}^{+}$(in purple) and $\mathrm{Myf5}^{-}$(in blue) progenitors after GFP $(82 \%)$, Myostatin $(80 \%, P=0.77)$, or SMAD7 $(80 \%, P=0.24)$ electroporation. $(N)$ In contrast, the proportion $\mathrm{MyoD}^{+}$muscle progenitors was significantly increased $(21 \%$, $\left.P<10^{-3}\right)$ or significantly decreased $\left(3 \%, P<10^{-2}\right) 84 \mathrm{~h}$ after Myostatin or SMAD7 electroporation, respectively, when compared with the control (12\%). Error bars indicate standard deviation. (d) Dermomyotome; (my) myotome. Bars: $D-F, 20 \mu \mathrm{m} ; A, B, G-M, 50 \mu \mathrm{m}$.

central part (Fig. 5A,B). Myostatin overexpression in the central dermomyotome induced a significant activation of p21 expression (Fig. 5C,D). The induction of p21 ex- pression in muscle progenitors was also visible in the myotome compartment $48 \mathrm{~h}$ after myostatin electroporation (Supplemental Fig. S3A-D). Thus, in agreement 
Manceau et al.
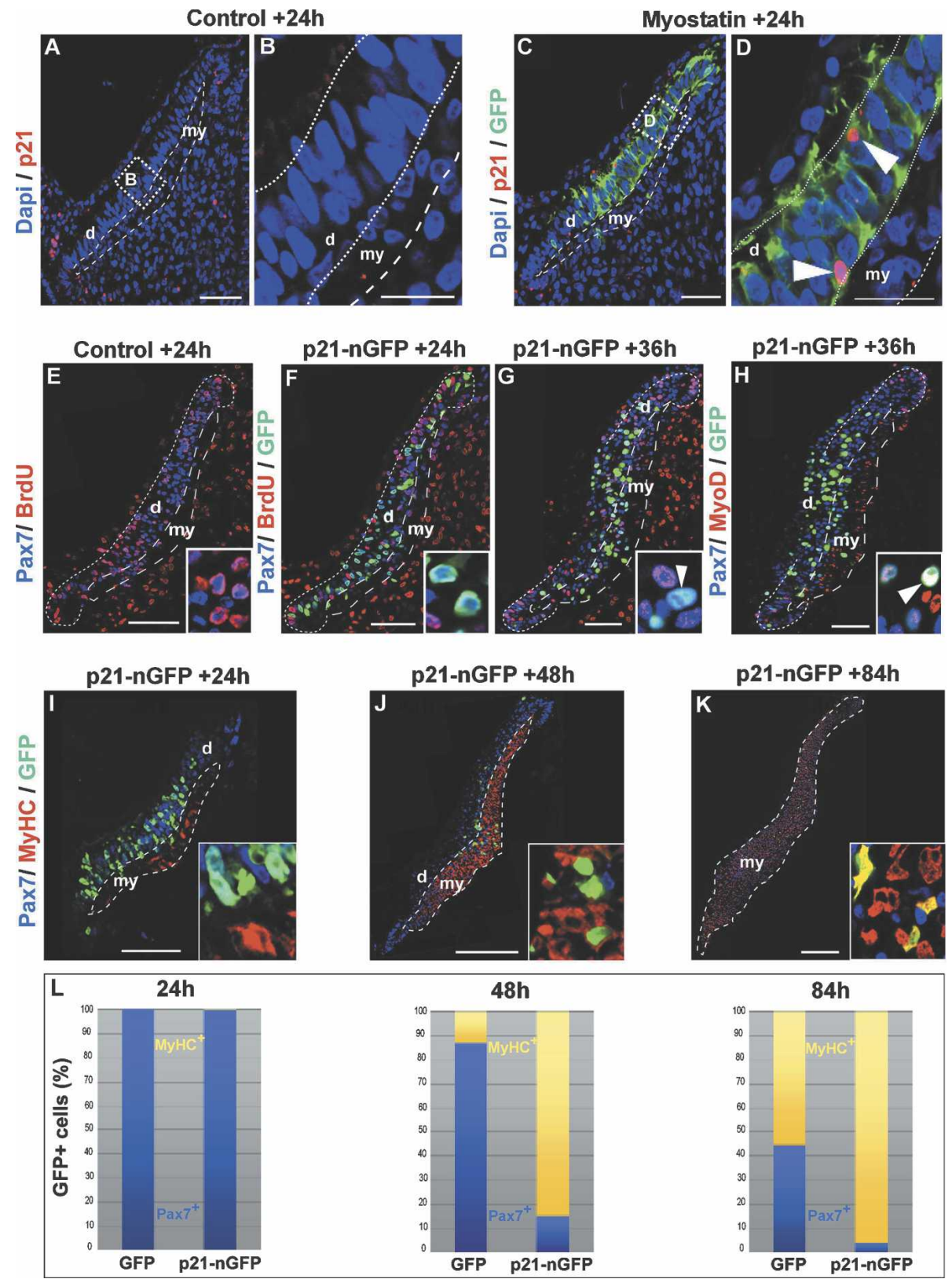

Figure 5. Myostatin signaling acts through $\mathrm{p} 21$ induction. $(C, D)$ Somites were electroporated with myostatin and analyzed $24 \mathrm{~h}$ after electroporation for GFP (in green), p21 (in red), and DAPI (in blue). $B$ and $D$ are enlargements of the zone delineated by white dotted lines in $A$ and $C$, respectively. While 21 is not detected in the central portion of the dermomyotome or in the myotome in control embryos $(A, B)$, it is up-regulated in myostatin-overexpressing cells $(C$; white arrowheads in $D)$. (E) Twenty-four hours after somite formation in control, nonelectroporated embryos, a large number of $\mathrm{Pax} 7^{+}$epithelial cells of the dermomyotome (in blue) were labeled with BrdU (in red), resulting in a purple color of nuclei (inset in E). In contrast, $24 \mathrm{~h}$ after the electroporation of a p21-nGFP construct in the central part of the dermomyotome $(F)$, all p21-GFP ${ }^{+} / \mathrm{Pax}^{+}$epithelial cells of the dermomyotome (in light blue) were BrdU ${ }^{-}($inset in $F)$. Thirty-six hours after p21-nGFP electroporation, $\operatorname{Pax} 7^{+}$cells that entered the myotome remained $B r d U^{-}(G$ and inset $)$, and expressed MyoD $(H)$, resulting in white nuclei (inset in $H)$. $(I-L)$ We quantified the proportion of Pax $7^{+} / \mathrm{GFP}^{+}\left(\right.$light blue) or MyHC $\mathrm{BH}^{+}$ $\mathrm{GFP}^{+}$(yellow) cells $24 \mathrm{~h}(I), 48 \mathrm{~h}(J)$, or $84 \mathrm{~h}(K)$ after p21-GFP or GFP-only electroporation. Insets at the bottom right show enlargements of the zone of counting. Cell counts are expressed as a percentage of $\mathrm{GFP}^{+}$cells. $(L)$ Twenty-four hours after $\mathrm{p} 21$ overexpression, the proportion of $\mathrm{Pax}^{+} / \mathrm{GFP}^{+}$progenitors was normal when compared with controls $(99 \%$ and $98 \%$, respectively). As muscle progenitors have entered the muscle compartment, there is a progressive exhaustion of the $\mathrm{p} 21-\mathrm{GFP}^{+} / \mathrm{Pax} 7^{+}$cell population $(L, 15 \%$ at 48 $\mathrm{h}, 4 \%$ at $84 \mathrm{~h}$ ) that becomes sparse within the muscle masses $(J, K)$. (d) Dermomyotome; (my) myotome (white dotted lines). Bars: $A-I$, $20 \mu \mathrm{m} ;, K, 200 \mu \mathrm{m}$. 
with the data obtained in in vitro studies, we show here that myostatin overexpression can induce p21 expression in vivo. Interestingly, the activation of p21 was observed only in a few cells within the myostatin-overexpressing population. To test the effect of $\mathrm{p} 21$ activation in the entire muscle progenitor population, we electroporated a p21-GFP fusion protein into the central part of the dermomyotome (Fig. 5E-L). Twenty-four hours after electroporation, none of the $\mathrm{p} 21-\mathrm{GFP}^{+}$cells within the epithelial dermomyotome incorporated BrdU (Fig. 5F), showing, as expected, that p21 induction in muscle progenitors induce their immediate cell cycle arrest. Pax7 expression was maintained in $\mathrm{p}^{2} 1^{+} / \mathrm{GFP}^{+}$dermomyotome cells (Fig. 5I,L), while Myf5, MyoD, or MyHC expression was not prematurely induced (Supplemental Fig. S3E,F), indicating that p21 induction does not activate the myogenic differentiation program before the dermomyotome undergoes EMT, similar to what we had observed when myostatin was overexpressed in the dermomyotome (Fig. 4D-F). We then characterized the identity of $\mathrm{p} 21-\mathrm{GFP}^{+}$cells after they had entered the muscle masses. Thirty-six hours after electroporation (i.e., immediately after the dermomyotome EMT), the p21-GFP ${ }^{+}$were $\mathrm{BrdU}^{-}$and maintained Pax7 expression (Fig. 5G). However, most of the p21-GFP ${ }^{+} / \mathrm{Pax}^{+}$cells coexpressed MyoD (Fig. $5 \mathrm{H}$ ), demonstrating that these cells are not in a quiescent status, but are actively engaged in the terminal differentiation program. Finally, we quantified the relative proportion of muscle progenitors and differentiated cells $3.5 \mathrm{~d}$ after after p 21 electroporation. We observed that virtually no p21-GFP ${ }^{+}$cells expressed Pax7 any longer within the muscle masses, while a vast majority of them expressed MyHC (Fig. $5 \mathrm{~K}, \mathrm{~L})$. These results demonstrate that p21 overexpression prevents the expansion of the muscle progenitors by provoking the initiation of their myogenic differentiation program once the progenitors have entered the myotome compartment. As a consequence of their premature differentiation, p21-GFP ${ }^{+}$cells became sparser in the growing muscles (Fig. 5J-L). These data demonstrate that p21 is sufficient to mimic the phenotype obtained when myostatin is overexpressed in the somite, and suggest that $\mathrm{p} 21$ is a target of myostatin signaling during normal development. Since it was shown that another Cdk inhibitor, p57, redundantly controls the in vivo differentiation of skeletal muscle together with p21 (Zhang et al. 1999), it is possible that both molecules mediate myostatin activity on embryonic muscle progenitors. Taken together, our results show that myostatin (likely through p21 activity) limits the expansion of the muscle progenitor pool by promoting terminal differentiation.

\section{Discussion}

In this study, we combined the electroporation technique with a battery of antibodies directed against markers for myogenic differentiation and cell proliferation to establish the sequence of the molecular events taking place in vivo as the muscle progenitors differentiate into fibers to contribute to the growth of muscle masses. This analysis was an essential prerequisite before undertaking an analysis of the role of myostatin signaling on this cell population. Importantly, the coexpression of the GFP reporter gene with the members of the myostatin signaling pathway has allowed us to track the progeny of muscle progenitors in vivo, and thus, to quantify their relative contribution to the developing muscle masses when myostatin signaling was altered. This, combined with stable retroviral infection and the analysis of mouse mutants, has allowed us to gain novel insights into the mode of action of myostatin. Our data show that myostatin signaling acts on embryonic muscle progenitors that have entered the muscle masses, and that are engaged in the muscle lineage (i.e, $\mathrm{Pax}^{+} / \mathrm{Myf}^{+}$muscle progenitors), to limit their proliferation by activating p21 and MyoD expression. Interestingly, p21 expression is observed in a salt-and-pepper pattern after myostatin overexpression. An hypothesis is that myostatin activates pulses of $\mathrm{p} 21$ expression that are observed only in a fraction of the population at any given time. This activation provokes the cell cycle arrest of muscle progenitors and their terminal differentiation into $\mathrm{MyHC}^{+}$ muscle fibers. Myostatin is thus an essential regulator of the balance between proliferation vs differentiation of embryonic muscle progenitors, thereby controlling the continuous growth of muscle masses throughout embryogenesis (Fig. 6A). We propose a new model to explain the phenotypes observed in genetically modified organisms in which myostatin signaling is perturbed. When myostatin is overexpressed, the premature activation of the terminal differentiation program causes a decrease in the number of embryonic muscle progenitors. In the long term, this leads to a decrease in the number of muscle fibers within muscle masses (muscle hypotrophy) (Fig. $6 \mathrm{~B})$. In contrast, the inhibition of myostatin delays the activation of the terminal differentiation program in muscle progenitors, which continue to proliferate. As a result, the number of muscle progenitors, (and, in the long term, the number of muscle fibers), is increased, leading to muscle hypertrophy (Fig. 6C).

The conclusion that myostatin promotes the terminal differentiation of muscle progenitors is in disagreement with in vivo studies performed previously, in which it was proposed, on the basis of experiments performed on the chick embryo, that myostatin signaling imposes reversible quiescence on embryonic muscle progenitors (Amthor et al. 2006). In this study, the implantation in the limb bud mesenchyme of beads coated with highly concentrated myostatin protein caused an arrest of muscle progenitor cell proliferation after implantation, as shown by the complete loss of BrdU incorporation in $\mathrm{Pax} 7^{+}$cells. Using the same model organism but a different paradigm to disturb myostatin signaling (i.e., electroporation technique, which represents a physiological way to express molecules within the muscle progenitor population), we never observed such a drastic cell cycle arrest, since the quantification of the BrdU incorporation in $\mathrm{Pax}^{+}$somitic or limb muscle progenitor cells after electroporation is undistinguishable in myostatin-overexpressing or control embryos. The differences between 


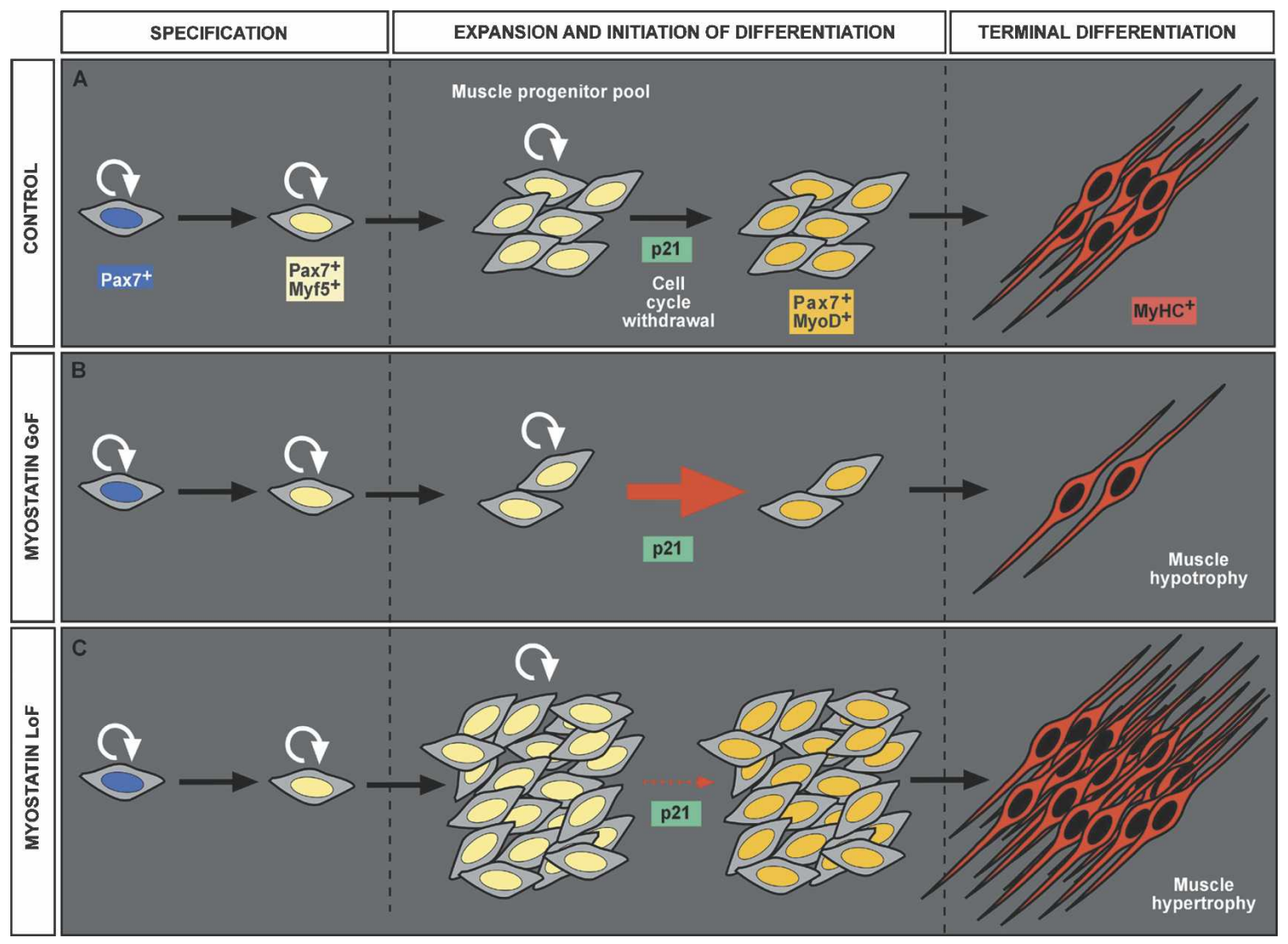

Figure 6. Model for the action of myostatin on embryonic muscle progenitors.

our data and those obtained in Amthor et al. (2006) are thus not due to a different response to myostatin exposure between muscle progenitors of the trunk and of the limb. When p21 (which is a likely downstream effector of myostatin, as shown by previously published in vitro studies and our data) is overexpressed in $\left(\operatorname{Pax} 7^{+}\right)$muscle progenitors, they stop proliferating. However, we clearly show by two different means that this does not reflect a reversible quiescent state: (1) We show that these $\mathrm{p} 21^{+} /$ $\mathrm{Brdu}^{-} / \mathrm{Pax} 7^{+}$cells within the muscle masses immediately activate MyoD, indicating that they are not quiescent, but on the contrary, they are actively engaged in the myogenic differentiation program; (2) by tracing the fate of these $\mathrm{p} 21^{+}$cells, we demonstrate that they eventually differentiate into functional $\mathrm{MyHC}^{+}$myofibers. The difference between our data suggesting that myostatin promotes terminal differentiation and that obtained in earlier studies suggesting that myostatin induces quiescence of progenitor cells may stem from high levels of signaling induced by high amounts of myostatin delivered on beads.

In vitro studies have shown that myostatin signaling acts by inhibiting the myogenic differentiation of myoblasts (Langley et al. 2002; Rios et al. 2002; Joulia et al. 2003; Kollias et al. 2006; Yang et al. 2006). Here, using an in vivo approach, we show that myostatin acts on embryonic resident muscle progenitors to promote their differentiation. Interestingly, when myostatin or its puta- tive effector p21 are overexpressed in the epithelial dermomyotome, the progenitor cells failed to engage in the myogenic program. In contrast, once in the muscle compartment, these cells prematurely turn on the expression of MRFs. The failure to initiate the myogenic program within the dermomyotome is not due to an incapacity of dermomyotome cells to activate MyoD expression, since they do so when exposed to appropriate inductive signals, such as SHH (Johnson et al. 1994; C. Marcelle, pers. observation). These data underline an interesting aspect of the mode of action of myostatin; i.e., the crucial importance of the environmental context in which the activity of myostatin on muscle differentiation is tested. The discrepancies between our results obtained in vivo and previous studies led in vitro could thus be explained by the fact that myostatin is not a crucial factor required to promote muscle differentiation, but rather puts muscle progenitors in a state in which they can respond to appropriate signals favoring muscle differentiation, which they find only in vivo, within the myotome. One such signal might be represented by the Notch signaling pathway that was shown to have an effect opposite to myostatin signaling on muscle progenitors (SchusterGossler et al. 2007; Vasyutina et al. 2007). That myostatin signaling does not modify the normal myogenic differentiation program, but only controls the moment at which terminal differentiation is initiated, is in agreement with data coming from transgenic mice in which 
myostatin signaling is overactivated or inactivated, since these animals do not exhibit impairment of the myogenic differentiation program (muscle fibers are present [Fig. 3L] and fully functional), but only modification of the muscle size (Fig. 3; McPherron et al. 1997).

Satellite cells of adult muscles, in addition to a common origin, share a number of cellular and molecular characteristics with embryonic muscle progenitors. One crucial difference is that they are relatively or totally quiescent and are only activated during the muscle regeneration process, while embryonic muscle progenitors actively proliferate and differentiate continuously to build muscles. Satellite cells express myostatin (McCroskery et al. 2003); however, the consequence of its action is likely to be different in the adult (where satellite cells maintain progenitor-like characteristics in spite of myostatin expression) and in the embryo (where it promotes terminal differentiation). It is possible that satellite cells do not undergo terminal differentiation because they are located in a particular "niche," being located under the basal lamina of muscle fibers, which shields them from the signals that would lead them to terminal differentiation. It is thus tempting to speculate that myostatin function leads to different phenotypes in the embryo and in the adult because of differences in the cellular environments.

In conclusion, our data significantly further our understanding of the mode of action of myostatin, a critical molecule in regulating muscle mass. Given the recent discovery that myostatin is a potential therapeutic target, our results may lead to novel insights of clinical value.

\section{Materials and methods}

\section{In situ hybridization and tissue sections}

Whole-mount in situ hybridizations on chick embryos were performed as described (Henrique et al. 1995). Probes used are a chicken myostatin probe (Amthor et al. 2002), a chicken follistatin probe (from Biotechnology and Biological Sciences Research Council [BBSRC] chick EST database, ChEST 977K1), a chicken Activin R2b probe (ChEST208G24), and a chicken SMAD7 probe (ChEST708B19). Mouse and chick embryos were embedded in a gelatine/sucrose solution and sectioned using a Cryostat (Leica CM 3050S).

\section{Electroporation}

Newly formed somites were electroporated as described previously (Scaal et al. 2004; Gros et al. 2005). To target the somitic muscle progenitors, electrodes were positioned so that only the dorsal part of interlimb somites, which give rise to the centralmost part of the dermomyotome, was electroporated. To target the forelimb muscle progenitors, electrodes were positioned so that only the lateral part of somites 16-22 were electroporated. The lineage analysis of the muscle progenitor population (Fig. 1; Supplemental Fig. S2) was performed using a construct encoding a cytoplasmic form of the GFP. Mouse myostatin cDNA was obtained by RT-PCR on total muscle RNA extracts. The oligonucleotides used were CGGATCCTCATGAGCACCCACAG CGGTCTAC $\left(3^{\prime}\right)$ and CTGCAAATGTATGTTATATTTACCT
GTTCAT $\left(5^{\prime}\right)$. Mouse myostatin, chicken follistatin (a kind gift of K. Patel), and mouse SMAD7 (a kind gift of S. Souchelnitskiy) cDNAs were subcloned into an electroporation vector that contains a membranal form of the GFP. The $\mathrm{p} 21$ protein fused to a nuclear form of GFP (p21-nGFP) (a kind gift of E. Prosperi and O. Cazzalini) was subcloned in the same vector. Ultraviolet light examination of embryos $24 \mathrm{~h}$ after electroporation allowed the screening of embryos: Only those showing a strong GFP signal in the central-most part of the dermomyotome (or in the lateral part of the dermomyotome for limb analyses) were kept for further analyses.

\section{Retroviral infections}

The mouse myostatin cDNA was subcloned into a RCAS$\mathrm{BP}(\mathrm{A}-2)$ vector and coelectroporated with the GFP into newly formed somites. To verify the extent of the retroviral infection, we stained sections of embryos that showed a strong GFP expression in the central part of the dermomyotome, $48 \mathrm{~h}$ after electroporation, with a p27 (=viral envelope protein) antibody. In situ hybridization with a mouse myostatin probe showed the strong overexpression of myostatin at that stage.

\section{Mouse embryos}

E15.5 mouse embryos were genotyped using the following primers: wild-type allele (220pb), 5'-AGAAGTCAAGGTGACAGA CACAC-3' and 5'-GGTGCACAAGATGAGTATGCGG-3'; and KO allele (332bp), 5' -GCATCGGCCATTGAACAAGAT-3' and 5'-GAGCAAGGTGAGATGACAGCA-3'.

\section{Antibodies, immunohistochemistry, and confocal analysis}

Phalloidin Alexa 456 (Molecular Probes) was used to detect FActin. Cell nuclei were stained with DAPI (Calbiochem). For immunohistochemistry on sections, the following antibodies were used: mouse monoclonal antibodies against Pax7 (Hybridoma Bank), Pax3 (Hybridoma Bank), Light Meromyosin (MF20, Hybridoma Bank); a rat monoclonal antibody against $\mathrm{BrdU}$ (Abcam); a chicken polyclonal antibody against GFP (Abcam); and rabbit polyclonal antibodies against p21 (Abcam), GFP (Torrey Pines Biolabs), and p27 (Charles River Laboratories).

To analyze cell division, embryos were exposed to BrdU for 1 $\mathrm{h}$ and sections were pretreated with $\mathrm{HCl}$ before antibody treatment. Stained sections were examined using a Zeiss LSM 510 Meta confocal microscope.

\section{Production of polyclonal antibodies to chicken MRFs}

The ORFs for chicken MyoD (CMD1), Myogenin, Myf5, and Mrf4 produced by PCR (TAQ or pfu polymerases) from the cDNA templates were cloned into the Pet21 (Novagen) or pRSET (Invitrogen) vectors. Full-length CMD1 was produced with a C-terminal his-6 tag in Pet21a. The remaining MRFs were expressed as full-length proteins with $\mathrm{N}$-terminal his-6 tags in the pRSET vectors. The proteins were analyzed by SDS gel electrophoresis and shown to be full-length MRFs with minimal degradation products or other contaminants. All of the MRFs bound the MCK right E-box in gel-shift assays. Rabbit polyclonal antibodies (produced by Hazelton Washington Laboratories) were tested for specificity by Western blot analysis using the four MRF proteins (100 ng to $1 \mu \mathrm{g}$ per lane) on the same blot challenged with a single MRF antibody in the presence of $10 \mu \mathrm{g} / \mathrm{mL}$ poly-L histidine (Sigma) to eliminate possible cross-reactivity by antibodies directed to the his- 6 tag. Each 
antibody was specific for the cognate MRF and no cross-reactivity was observed.

\section{Acknowledgments}

We thank Drs. Cliff Tabin and Thomas Lecuit for helpful comments on the manuscript. This study was funded by grants from the Actions Concertées Incitatives (ACI) and the Association Française contre les Myopathies (AFM), and by the EEU 6th Framework Programme Network of Excellence MYORES. J.G. and M.M. were Fellows from the Ministère de la Recherche et des Technologies (MRT).

\section{References}

Amthor, H., Huang, R., McKinnell, I., Christ, B., Kambadur, R., Sharma, M., and Patel, K. 2002. The regulation and action of myostatin as a negative regulator of muscle development during avian embryogenesis. Dev. Biol. 251: 241-257.

Amthor, H., Nicholas, G., McKinnell, I., Kemp, C.F., Sharma, M., Kambadur, R., and Patel, K. 2004. Follistatin complexes Myostatin and antagonises Myostatin-mediated inhibition of myogenesis. Dev. Biol. 270: 19-30.

Amthor, H., Otto, A., Macharia, R., McKinnell, I., and Patel, K. 2006. Myostatin imposes reversible quiescence on embryonic muscle precursors. Dev. Dyn. 235: 672-680.

Ben-Yair, R. and Kalcheim, C. 2005. Lineage analysis of the avian dermomyotome sheet reveals the existence of single cells with both dermal and muscle progenitor fates. Development 132: 689-701.

Bogdanovich, S., Krag, T.O., Barton, E.R., Morris, L.D., Whittemore, L.A., Ahima, R.S., and Khurana, T.S. 2002. Functional improvement of dystrophic muscle by myostatin blockade. Nature 420: 418-421.

Buckingham, M., Bajard, L., Chang, T., Daubas, P., Hadchouel, J., Meilhac, S., Montarras, D., Rocancourt, D., and Relaix, F. 2003. The formation of skeletal muscle: From somite to limb. J. Anat. 202: 59-68.

Clop, A., Marcq, F., Takeda, H., Pirottin, D., Tordoir, X., Bibe, B., Bouix, J., Caiment, F., Elsen, J.M., Eychenne, F., et al. 2006. A mutation creating a potential illegitimate microRNA target site in the myostatin gene affects muscularity in sheep. Nat. Genet. 38: 813-818.

Delfini, M.C., Hirsinger, E., Pourquié, O., and Duprez, D. 2000. Delta 1-activated notch inhibits muscle differentiation without affecting Myf5 and Pax3 expression in chick limb myogenesis. Development 127: 5213-5224.

Dulic, V., Stein, G.H., Far, D.F., and Reed, S.I. 1998. Nuclear accumulation of p21Cip1 at the onset of mitosis: A role at the G2/M-phase transition. Mol. Cell. Biol. 18: 546-557.

Grobet, L., Martin, L.J., Poncelet, D., Pirottin, D., Brouwers, B., Riquet, J., Schoeberlein, A., Dunner, S., Menissier, F., Massabanda, J., et al. 1997. A deletion in the bovine myostatin gene causes the double-muscled phenotype in cattle. Nat. Genet. 17: 71-74.

Gros, J., Scaal, M., and Marcelle, C. 2004. A two-step mechanism for myotome formation in chick. Dev. Cell 6: 875-882.

Gros, J., Manceau, M., Thome, V., and Marcelle, C. 2005. A common somitic origin for embryonic muscle progenitors and satellite cells. Nature 435: 954-958.

Henrique, D., Adam, J., Myat, A., Chitnis, A., Lewis, J., and Ish-Horowicz, D. 1995. Expression of a Delta homologue in prospective neurons in the chick. Nature 375: 787-790.

Johnson, R.L., Laufer, E., Riddle, R.D., and Tabin, C. 1994. Ec- topic expression of Sonic hedgehog alters dorsal-ventral patterning of somites. Cell 79: 1165-1173.

Joulia, D., Bernardi, H., Garandel, V., Rabenoelina, F., Vernus, B., and Cabello, G. 2003. Mechanisms involved in the inhibition of myoblast proliferation and differentiation by myostatin. Exp. Cell Res. 286: 263-275.

Kambadur, R., Sharma, M., Smith, T.P., and Bass, J.J. 1997. Mutations in myostatin (GDF8) in double-muscled Belgian Blue and Piedmontese cattle. Genome Res. 7: 910-916.

Kassar-Duchossoy, L., Giacone, E., Gayraud-Morel, B., Jory, A., Gomes, D., and Tajbakhsh, S. 2005. Pax3/Pax7 mark a novel population of primitive myogenic cells during development. Genes \& Dev. 19: 1426-1431.

Kollias, H.D., Perry, R.L., Miyake, T., Aziz, A., and McDermott, J.C. 2006. Smad7 promotes and enhances skeletal muscle differentiation. Mol. Cell. Biol. 26: 6248-6260.

Langley, B., Thomas, M., Bishop, A., Sharma, M., Gilmour, S., and Kambadur, R. 2002. Myostatin inhibits myoblast differentiation by down-regulating MyoD expression. I. Biol. Chem. 277: 49831-49840.

Lee, S.J. and McPherron, A.C. 2001. Regulation of myostatin activity and muscle growth. Proc. Natl. Acad. Sci. 98: 93069311.

Matzuk, M.M., Lu, N., Vogel, H., Sellheyer, K., Roop, D.R., and Bradley, A. 1995. Multiple defects and perinatal death in mice deficient in follistatin. Nature 374: 360-363.

McCroskery, S., Thomas, M., Maxwell, L., Sharma, M., and Kambadur, R. 2003. Myostatin negatively regulates satellite cell activation and self-renewal. J. Cell Biol. 162: 1135-1147.

McPherron, A.C. and Lee, S.J. 1997. Double muscling in cattle due to mutations in the myostatin gene. Proc. Natl. Acad. Sci. 94: 12457-12461.

McPherron, A.C., Lawler, A.M., and Lee, S.J. 1997. Regulation of skeletal muscle mass in mice by a new TGF- $\beta$ superfamily member. Nature 387: 83-90.

Reisz-Porszasz, S., Bhasin, S., Artaza, J.N., Shen, R., Sinha-Hikim, I., Hogue, A., Fielder, T.J., and Gonzalez-Cadavid, N.F. 2003. Lower skeletal muscle mass in male transgenic mice with muscle-specific overexpression of myostatin. Am. J. Physiol. Endocrinol. Metab. 285: E876-E888. doi: 10.1152/ ajpendo.00081.2003.

Relaix, F., Rocancourt, D., Mansouri, A., and Buckingham, M. 2005. A Pax3/Pax7-dependent population of skeletal muscle progenitor cells. Nature 435: 948-953.

Rios, R., Carneiro, I., Arce, V.M., and Devesa, J. 2002. Myostatin is an inhibitor of myogenic differentiation. Am. J. Physiol. Cell Physiol. 282: C993-C999. doi: 10.1152/ajpcell.00372. 2001.

Sabourin, L.A. and Rudnicki, M.A. 2000. The molecular regulation of myogenesis. Clin. Genet. 57: 16-25.

Scaal, M., Gros, J., Lesbros, C., and Marcelle, C. 2004. In ovo electroporation of avian somites. Dev. Dyn. 229: 643-650.

Schienda, J., Engleka, K.A., Jun, S., Hansen, M.S., Epstein, J.A., Tabin, C.J., Kunkel, L.M., and Kardon, G. 2006. Somitic origin of limb muscle satellite and side population cells. Proc. Natl. Acad. Sci. 103: 945-950.

Schuelke, M., Wagner, K.R., Stolz, L.E., Hubner, C., Riebel, T., Komen, W., Braun, T., Tobin, J.F., and Lee, S.J. 2004. Myostatin mutation associated with gross muscle hypertrophy in a child. N. Engl. J. Med. 350: 2682-2688.

Schuster-Gossler, K., Cordes, R., and Gossler, A. 2007. Premature myogenic differentiation and depletion of progenitor cells cause severe muscle hypotrophy in Deltal mutants. Proc. Natl. Acad. Sci. 104: 537-542.

Sherr, C.J. and Roberts, J.M. 1999. CDK inhibitors: Positive and negative regulators of G1-phase progression. Genes \& Dev. 
13: $1501-1512$.

Taylor, W.E., Bhasin, S., Artaza, J., Byhower, F., Azam, M., Willard Jr., D.H., Kull Jr., F.C., and Gonzalez-Cadavid, N. 2001. Myostatin inhibits cell proliferation and protein synthesis in C2C12 muscle cells. Am. J. Physiol. Endocrinol. Metab. 280: E221-E228.

Thomas, M., Langley, B., Berry, C., Sharma, M., Kirk, S., Bass, J., and Kambadur, R. 2000. Myostatin, a negative regulator of muscle growth, functions by inhibiting myoblast proliferation. J. Biol. Chem. 275: 40235-40243.

Vasyutina, E., Lenhard, D.C., Wende, H., Erdmann, B., Epstein, J.A., and Birchmeier, C. 2007. RBP-J (Rbpsuh) is essential to maintain muscle progenitor cells and to generate satellite cells. Proc. Natl. Acad. Sci. 104: 4443-4448.

Yang, W., Chen, Y., Zhang, Y., Wang, X., Yang, N., and Zhu, D. 2006. Extracellular signal-regulated kinase $1 / 2$ mitogen-activated protein kinase pathway is involved in myostatinregulated differentiation repression. Cancer Res. 66: 13201326.

Zhang, P., Wong, C., Liu, D., Finegold, M., Harper, J.W., and Elledge, S.J. 1999. p21(CIP1) and p57(KIP2) control muscle differentiation at the myogenin step. Genes \& Dev. 13: 213 224.

Zimmers, T.A., Davies, M.V., Koniaris, L.G., Haynes, P., Esquela, A.F., Tomkinson, K.N., McPherron, A.C., Wolfman, N.M., and Lee, S.J. 2002. Induction of cachexia in mice by systemically administered myostatin. Science 296: $1486-$ 1488. 


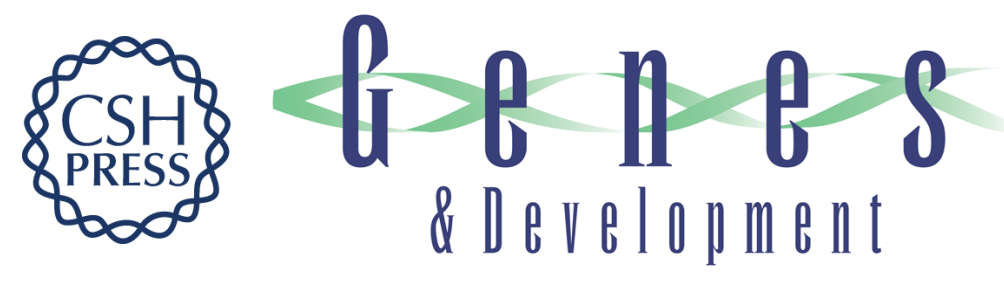

\section{Myostatin promotes the terminal differentiation of embryonic muscle progenitors}

Marie Manceau, Jérôme Gros, Kathleen Savage, et al.

Genes Dev. 2008, 22:

Access the most recent version at doi:10.1101/gad.454408

Supplemental http://genesdev.cshlp.org/content/suppl/2008/02/19/22.5.668.DC1
Material

References This article cites 39 articles, 17 of which can be accessed free at: http://genesdev.cshlp.org/content/22/5/668.full.html\#ref-list-1

License

Email Alerting Receive free email alerts when new articles cite this article - sign up in the box at the top Service right corner of the article or click here.

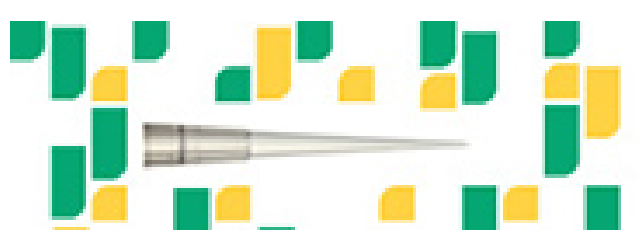

Focused on your science. 